\title{
Experiment and Simulation Study on the Special Phase Behavior of Huachang Near-Critical Condensate Gas Reservoir Fluid
}

\author{
Dali Hou, ${ }^{1,2}$ Yang Xiao, ${ }^{1,2}$ Yi Pan, ${ }^{3}$ Lei Sun, ${ }^{3}$ and Kai Li1,2 \\ ${ }^{1}$ School of Energy, Chengdu University of Technology, Chengdu, Sichuan 610059, China \\ ${ }^{2}$ State Key Laboratory of Oil and Gas Reservoir Geology and Exploitation, Chengdu University of Technology, Chengdu, \\ Sichuan 610059, China \\ ${ }^{3}$ State Key Laboratory of Oil and Gas Reservoir Geology and Exploitation, Southwest Petroleum, University of Technology, \\ Chengdu, Sichuan 610500, China \\ Correspondence should be addressed to Yang Xiao; yangxiao20142015@126.com
}

Received 5 November 2015; Revised 16 January 2016; Accepted 10 February 2016

Academic Editor: Casimiro Mantell

Copyright (C) 2016 Dali Hou et al. This is an open access article distributed under the Creative Commons Attribution License, which permits unrestricted use, distribution, and reproduction in any medium, provided the original work is properly cited.

\begin{abstract}
Due to the special phase behavior of near-critical fluid, the development approaches of near-critical condensate gas and near-critical volatile oil reservoirs differ from conventional oil and gas reservoirs. In the near-critical region, slightly reduced pressure may result in considerable change in gas and liquid composition since a large amount of gas or retrograde condensate liquid is generated. It is of significance to gain insight into the composition variation of near-critical reservoir during the depletion development. In our study, we performed a series of $P V T$ experiments on a real near-critical gas condensate reservoir fluid. In addition to the experimental studies, a commercial simulator combined with the PREOS model was utilized to study retrograde condensate characteristics and reevaporation mechanism of condensate oil with $\mathrm{CO}_{2}$ injection based on vapor-liquid phase equilibrium thermodynamic theory. The research shows that when reservoir pressure drops below a certain pressure, the variation of retrograde condensate liquid saturation of the residual reservoir fluid exhibits the phase behavior of volatile oil.
\end{abstract}

\section{Introduction}

In recent years, amounts of critical/near-critical oil and gas reservoirs were both found in China and abroad [1]. The phase behavior of near-critical fluid has received close attention because of its complex and fickle fluid properties, and a large number of studies were conducted on binary or ternary systems; the study on a multicomponent reservoir fluid is very scarce [2]. Gil et al. measured the density of $\mathrm{CO}_{2}$ $\mathrm{C}_{2} \mathrm{H}_{6}$ binary mixture at the critical region and supercritical region and compared the measured data with the data from references [3]. A. R. Bazaev and E. A. Bazaev reviewed the $P V T$ parameters of some binary mixtures at the near-critical region and measured the $P V T$ parameters of four groups of binary mixtures at near-critical region [4]. However, only a few scholars performed the phase behavior experiments and theoretical research on multicomponent mixtures at nearcritical region [5-14]. Yang et al. measured PVT physical parameters, including deviation factor, bubble point and dew point at the critical region, critical point, volume fraction of liquid at the two-phase region, and density of gas and fluid phase, of real multicomponent formation fluid in reservoirs at the near-critical region through experiments [5]. Luo and Zhong explained the layering effect of synthetic near-critical condensate gas reservoir fluid in $P V T$ cell and demonstrated graded distribution of near-critical fluid density with height using optical principle. Results indicate that great compressibility of near-critical fluid and gravity result in great density gradient and that it is hard for fluid to reach balance within a short time because of wide transition zone area between twophase fluid at near-critical region and distinct fluctuations [6]. Zheng et al. measured phase behavior at near-critical region of three rich condensate gas pools: one is synthetic 6component rich condensate gas reservoir fluid sample and the other two are fluid samples from real offshore rich condensate gas pool and land rich condensate gas pool, respectively. Critical point, bubble/dew point curve, critical opalescence phenomena, and phase transition at critical region were 
tested. Test results indicate that two dew points occur at temperatures higher than critical point and transition between dew point and bubble point at temperatures lower than critical point, namely, transition from dew point into bubble point, and behaviors of synthetic fluid sample and real formation fluid sample at near-critical region are different: near-critical region of real formation fluid sample is wider and becomes wider when paraffin content in fluid is greater [7-9]. Parra and Remolina used synthetic 4-component nearcritical volatile oil fluid to study $P V T$ phase behavior after injection of $\mathrm{N}_{2}$. Results indicate that saturation pressure of near-critical volatile oil fluid increases with increasing $\mathrm{N}_{2}$ injection ratio and crude oil density decreases with increasing gas/oil ratio and near-critical volatile oil fluid transformed into near-critical condensate gas fluid at $\mathrm{N}_{2}$ injection of $40 \mathrm{~mol} \%$. Above results indicate that researches on multicomponent near-critical fluid phase behavior were mainly focused on synthetic multicomponent fluid and scarcely focused on real multicomponent formation fluid; what is more, researches on multicomponent near-critical fluid phase behavior were mainly focused on experiment and scarcely focused on theory and stimulation [10].

Therefore, in this paper, phase behavior experiment was performed on a real near-critical reservoir fluid; the phase behavior experiment includes two-flash experiment: constant composition expansion experiment and constant volume depletion experiment. In addition, we also conducted a series of numerical simulations, which includes two-flash experiment, constant composition expansion experiment, constant volume depletion experiment, and $\mathrm{CO}_{2}$-injection swelling test. The experimental and simulation results provide basic data for further research on phase behavior characteristics and thermodynamic model of near-critical complex fluid, also provide basic data for determining the minimum miscible pressure in $\mathrm{CO}_{2}$ miscible flooding of the near-critical complex fluid, and provide reference for enhancing recovery of retrograde condensate oil by injecting $\mathrm{CO}_{2}$ in near-critical condensate gas reservoirs [15].

\section{Experiment}

2.1. Sample Preparation. Experimental measurements were made on the Huachang reservoir fluid, and the fluid of H2-3 well was selected, which was directly taken from the surface of the gas-liquid separator of H2-3 well in Huachang oil field in the south of China. Under original reservoir condition $\left(132.4^{\circ} \mathrm{C}, 25.53 \mathrm{MPa}\right)$ and initial gas-oil ratio, the representative fluid sample was prepared by using the surface separator oil and separator gas. All our operations comply with the standard of gas condensate reservoir fluid properties analysis (SY/T5542-2009) [16]. Table 1 shows the well stream composition of reservoir fluid based on the results of gas and oil chromatographic analysis and measured gas-oil ratio. As is shown in Table 1, the content of intermediate hydrocarbon components is about $25.66 \mathrm{~mol} \%$ and combined with the gas-oil ratio $\left(869.00 \mathrm{~m}^{3} / \mathrm{m}^{3}\right)$ and the content of condensate oil $\left(702.90 \mathrm{~g} / \mathrm{m}^{3}\right)$, so the reservoir fluid of $\mathrm{H} 2-3$ well is considered to be a near-critical condensate gas reservoir fluid system with a low gas-oil ratio and high content of
TABLE 1: Well stream composition for $\mathrm{H} 2-3$ well.

\begin{tabular}{lc}
\hline Component & mol\% \\
\hline $\mathrm{N}_{2}$ & 0.636 \\
$\mathrm{CO}_{2}$ & 5.228 \\
$\mathrm{C}_{1}$ & 57.067 \\
$\mathrm{C}_{2}$ & 11.732 \\
$\mathrm{C}_{3}$ & 6.224 \\
$\mathrm{iC}_{4}$ & 1.075 \\
$\mathrm{nC}_{4}$ & 1.756 \\
$\mathrm{iC}_{5}$ & 1.207 \\
$\mathrm{nC}_{5}$ & 1.086 \\
$\mathrm{C}_{6}$ & 2.580 \\
$\mathrm{C}_{7+}$ & 11.411 \\
\hline & \\
\hline Density of $\mathrm{C}_{7+}, \mathrm{g} / \mathrm{cm}^{3}$ & 0.754 \\
Molecular weight of $\mathrm{C}_{7+}$, g/mol & 114.4 \\
\hline
\end{tabular}

intermediate hydrocarbon and high content of condensate oil.

2.2. Apparatus. For conducting the PVT experiment of nearcritical condensate gas reservoir fluid system, a full observation mercury-free high temperature and high pressure multifunctional reservoir fluid analyzer JEFRI which was developed and produced by Canadian DBR Company was adopted. A schematic of the apparatus is shown in Figure 1. It consists of an injection pump system, a $150 \mathrm{~mL}$ overall visual PVT cell (the temperature ranges from $0^{\circ} \mathrm{C}$ to $200^{\circ} \mathrm{C}$ with an uncertainty of $0.1^{\circ} \mathrm{C}$, and pressure ranges from $0.1 \mathrm{MPa}$ to $70 \mathrm{MPa}$ with an uncertainty of $0.01 \mathrm{MPa}$ ), a flash separation, a temperature control system, an oil/gas chromatography, and an electronic balance. The PVT cell is equipped with a tight fit cone piston at the bottom, so that a small annular space volume is formed between cylinder wall and piston, which can accurately measure a very small amount of retrograde condensate liquid dropout of the sample through the external altimeter. And by way of video, it allows us to observe the whole phase behavior of the near-critical condensate gas reservoir fluid.

\subsection{Experimental Procedure}

(1) Clean PVT vessel and cells; then connect the PVT vessel to cells and evacuate the cells.

(2) Prepare the near-critical condensate gas sample, and control and maintain the desired temperature using the constant temperature air bath.

(3) Transfer a certain amount (about $40 \mathrm{~mL}$ ) of the synthetic near-critical condensate gas sample into PVT cells at the specified temperature and pressure, adjust the oven through thermostat to the reservoir temperature, stir the condensate gas sample for 1 hour, and then maintain for $30 \mathrm{~min}$ and measure the nearcritical condensate gas sample volume of the PVT cells. 


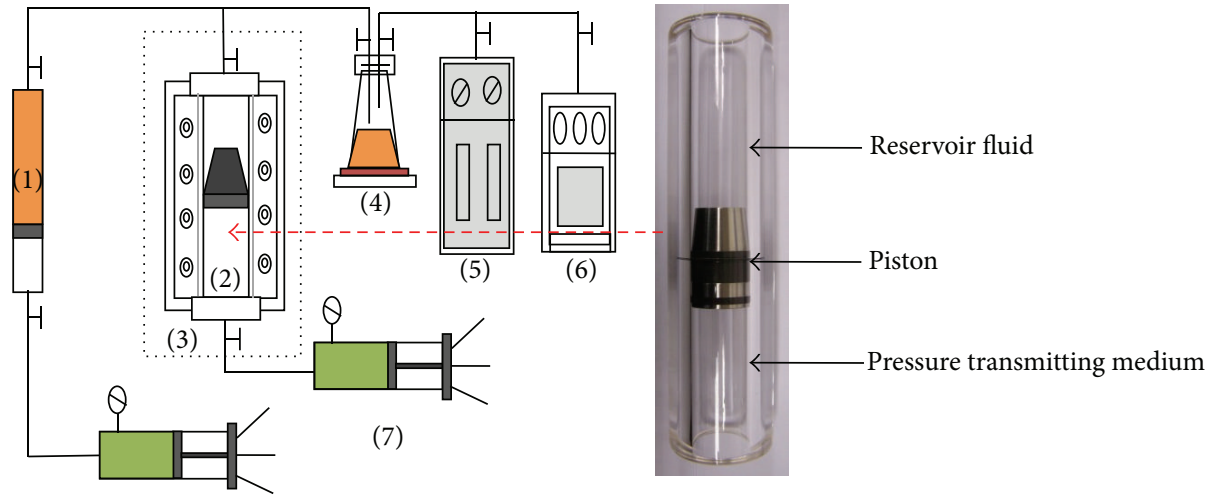

(1) Condensate gas sample

(2) PVT cell

(3) Thermostatic system

(4) Oil and gas separation devices and electronic balance
(5) Gasometer

(6) Oil and gas chromatography

(7) Automatic pump

FIGURE 1: Schematic diagram of the experimental apparatus.

(4) After transferring the prepared sample to PVT cells, under reservoir condition, the stable fluid was slowly released to laboratory temperature and atmospheric conditions from the PVT cells, and gas and liquid separated. Record the bled gas volumes using the gasometer and the bled oil volumes using the electronic balance and density meter and remaining gas volumes of $P V T$ vessel.

(5) The following step is prepared for the constant composition expansion experiment on the remaining gas volumes of $P V T$ vessel. The remaining gas sample in the PVT vessel was depressurized step by step from the reservoir pressure under the formation temperature; record the value of pressure and volume.

(6) Finally, the constant volume depletion experiment was conducted. It is evenly divided into $6 \sim 8$ pressure drop between the dew point pressure and the proposed abandonment pressure under the formation temperature. Depressurize to the each desirable pressure and balance the system for half an hour or more and then record the total volume of the sample and the volume of the condensate oil in the PVT cell.

The detailed testing of the process of each experiment and testing purposes are as follows:

(1) Two-flash experiment: the testing procedures are described in step (4). Besides, chromatographic analysis (HP-6890 gas chromatograph and an Agilent7890A oil chromatograph) of the separated gas and liquid was conducted to identify composition of reservoir fluid system. The testing purpose is to obtain the well stream components and gas-oil ratio.

(2) Constant composition expansion experiment (CCE experiment). Constant composition expansion experiment is also known as $P-V$ test. The testing purpose is to provide information on determination of dew point, gas deviation factor, and relative volume of the fluid at different pressures. The testing procedures are described in step (5). In the CCE test, the gradual step-down approximation method is used to determine the dew point pressure, when the pressure differences between a fine mist droplet existing and disappearing is less than $0.1 \mathrm{MPa}$, take the average value of these two pressures for the dew point pressure. To test the $P-V$ relationship, the sample in the container was pressurized to the reservoir pressure $(25.53 \mathrm{MPa})$ under the formation temperature $\left(132.4^{\circ} \mathrm{C}\right)$ and sufficiently stirred until stability. Then reduce the pressure step by step at reservoir temperature, during which the change in volume is obtained. When pressure drops below the dew point, retrograde condensate liquid drops out.

(3) Constant volume depletion experiment (CVD experiment). The testing purpose is to predict the change of the condensate oil saturation, the change of produced well stream components, and residual liquid well stream components in the process of depletion development of the condensate gas reservoir. The testing procedures are described in step (5). In the CVD test, the volume of the sample at dew point pressure is identified as the constant fluid pore volume of gas condensate reservoir and the volume is expressed as $V_{d}$ (it is used to calculate the condensate oil saturation and the condensate oil and gas recovery). And dew point pressure to zero pressure (gauge pressure, $0.1 \mathrm{MPa}$ ) is divided into eight pressure stages to simulate the depletion process of the reservoir, and each time (each pressure stage, which is $25.53 \mathrm{MPa}, 24.48 \mathrm{MPa}, 22 \mathrm{MPa}, 20 \mathrm{MPa}, 17 \mathrm{MPa}$, $14 \mathrm{MPa}, 11 \mathrm{MPa}, 8 \mathrm{MPa}$, and $5 \mathrm{MPa}$ ) the system was allowed to equilibrate. Since the pressure reduced, the gas expanded, discharging the gas until reaching the constant volume $V_{d}$ at each constant pressure. 
TABLE 2: Composition of pseudo-components.

\begin{tabular}{lc}
\hline Pseudo-components & mol\% \\
\hline $\mathrm{CO}_{2}$ & 5.23 \\
$\mathrm{~N}_{2}$ & 0.64 \\
$\mathrm{CH}_{4}$ & 57.07 \\
$\mathrm{C}_{2} \mathrm{H}_{6}$ & 11.73 \\
$\mathrm{C}_{3} \mathrm{H}_{8}$ & 6.22 \\
$\mathrm{iC}_{4} \mathrm{H}_{10}$ & 1.07 \\
$\mathrm{nC}_{4} \mathrm{H}_{10}$ & 1.76 \\
$\mathrm{iC}_{5} \mathrm{H}_{12}$ & 1.21 \\
$\mathrm{nC}_{5} \mathrm{H}_{12}$ & 1.09 \\
$\mathrm{C}_{6} \mathrm{H}_{14}$ & 2.58 \\
$\mathrm{C}_{7} \sim \mathrm{C}_{8}$ & 7.74 \\
$\mathrm{C}_{9} \sim \mathrm{C}_{10}$ & 2.49 \\
$\mathrm{C}_{11+}$ & 1.18 \\
\hline
\end{tabular}

Repeat the depressurization-exhaust process till the last stage of pressure. The testing process of the last level pressure to zero pressure is described as follows: open the top valve and directly depressurize to zero pressure by gas releasing. Subsequently, discharge the residual oil and gas from the cell and take the gas sample to conduct the component analysis, and the density and composition of residual oil were simultaneously measured.

\section{Calculations}

To verify the laboratory results, we utilized the high precision PR equation of state (PREOS78) [17] in WINPROP module of the Computer Modeling Group (CMG) simulator. Combined with the fluid thermodynamic equilibrium theory, it can accurately describe and predict phase behavior of condensate gas reservoir fluid and phase transition near the critical point. Thermodynamic parameters of the PREOS are adjusted to match the experimental measured $P V T$ data. The original well stream composition was split and grouped into 13 pseudo-components, which is given in Table 2. Critical temperatures, critical pressures, and acentric factors of the plus components and binary interaction parameters $\left(K_{i j}\right)$ were adjusted to match the experimental data, such as the saturation pressure (the dew point pressure), gas-oil ratio, relative volumes, and retrograde condensate liquid saturations. It is worth mentioning that interaction coefficients $\left(K_{i j}\right)$ are introduced to account for the molecular interaction between dissimilar molecules. The values of the interaction coefficients are obtained by fitting the predicted saturation pressures to experimental data through the PR78 EOS. Tables 3 and 4 present the adjusted critical temperatures, critical pressures, and acentric factors of the plus components and obtained binary interaction parameters. The absolute relative error (1) and the average absolute relative error (2) are used to express the deviation between the calculated values by using the PREOS in this paper and the experimental measured values. The objective is to make the deviation between the calculated value and experimental value minimum. To extend the laboratory results, on the basis of fitting the experimental data, a series of simulation calculations were carried out, such as the component variation of remaining fluid, condensate oil, condensate gas in CVD experiment, and reevaporation mechanism of remaining fluid with $\mathrm{CO}_{2}$ injection

$$
\begin{aligned}
\text { ARE } \% & =\sum_{i=1}^{N}\left|\frac{\text { Cal }-\operatorname{Exp}}{\operatorname{Exp}}\right|_{i} \times 100, \\
\text { AARE } \% & =\frac{1}{N} \sum_{i=1}^{N}\left|\frac{\text { Cal }-\operatorname{Exp}}{\operatorname{Exp}}\right|_{i} \times 100 .
\end{aligned}
$$

\section{Results and Discussion}

4.1. Experimental Results and Discussion. Prior to constant composition expansion (CCE) and constant volume depletion (CVD) experiment, a two-flash experiment of the reservoir fluid of H2-3 well was performed. Table 5 shows the twoflash experimental data of the reservoir fluid of H2-3 well. Referring to the international standard, the fluid is identified as near-critical condensate gas reservoir fluid system, which has high content of condensate oil, low condensate oil density, and gas-oil ratio.

Constant composition expansion experiment is also known as $P-V$ relationship experiment, which provides information on determination of dew point, relative volume of the fluid, and retrograde condensate liquid saturation at different pressures. Relative volume is the ratio between the volume of each pressure and the volume of dew point pressure, and the retrograde condensate liquid saturation is the ratio between the volume of the retrograde condensate oil and the volume of the dew point pressure. The CCE experimental results under reservoir temperature $\left(132.4^{\circ} \mathrm{C}\right)$ are showed in Table 6, the reservoir fluid of H2-3 well exhibits a maximum retrograde condensate liquid saturation of $42.079 \%$, and the retrograde condensate liquid saturation increases first and then decreases.

Meanwhile, we observed the phase behavior of H2-3 well reservoir fluid in the near-critical region during CCE experiment. Figure 2 presents the phase behavior in the near-critical region of reservoir fluid in $\mathrm{H} 2-3$ well during pressure drop process. Under the formation temperature, when pressure reduces from the pressure point in Figure 2(a) to the pressure point in Figures 2(b), 2(c), 2(d), 2(e), and 2(f), reservoir fluid in $P V T$ test cell turns from transparent golden yellow into light brown and then into reddish brown and finally into completely opaque ash black. When pressure reduces from the pressure point in Figure 2(f) to the pressure point in Figures 2(g) and 2(h), reservoir fluid in PVT test cell turns from completely opaque ash black into reddish brown at bottom and ash black at top and then into light brown at bottom and light ash black at top, and does not have the obvious gas-liquid interface. When pressure further reduces from the pressure point in Figure 2(h) to the pressure point in Figures 2(i), 2(j), and 2(k), reservoir fluid in PVT test cell turns from light brown at bottom and light ash black at top into golden yellow at bottom and has the obvious gasliquid interface; besides, retrograde condensate liquid volume 
TABLE 3: Critical temperatures and critical pressures, acentric factors of the plus components.

\begin{tabular}{lccc}
\hline Plus components & Critical temperature $/\left({ }^{\circ} \mathrm{C}\right)$ & Critical pressure/(MPa) & Acentric factor \\
\hline $\mathrm{C}_{7} \sim \mathrm{C}_{8}$ & 280.31 & 3.0245 & 0.283 \\
$\mathrm{C}_{9} \sim \mathrm{C}_{10}$ & 336.85 & 2.4608 & 0.368 \\
$\mathrm{C}_{11+}$ & 401.39 & 2.1066 & 0.477 \\
\hline
\end{tabular}

TABLE 4: Binary interaction parameters $\left(K_{i j}\right)$ and mixing rules for the PREOS in this study.

\begin{tabular}{lcccccccccccccc}
\hline Components & $\mathrm{CO}_{2}$ & $\mathrm{~N}_{2}$ & $\mathrm{CH}_{4}$ & $\mathrm{C}_{2} \mathrm{H}_{6}$ & $\mathrm{C}_{3} \mathrm{H}_{8}$ & $\mathrm{iC}_{4} \mathrm{H}_{10}$ & $\mathrm{nC}_{4} \mathrm{H}_{10}$ & $\mathrm{iC}_{5} \mathrm{H}_{12}$ & $\mathrm{nC}_{5} \mathrm{H}_{12}$ & $\mathrm{C}_{6} \mathrm{H}_{14}$ & $\mathrm{C}_{7} \sim \mathrm{C}_{8}$ & $\mathrm{C}_{9} \sim \mathrm{C}_{10}$ & $\mathrm{C}_{11+}$ \\
\hline $\mathrm{CO}_{2}$ & 0 & 0.0200 & 0.1030 & 0.1300 & 0.1350 & 0.1300 & 0.1300 & 0.1250 & 0.1250 & 0.1500 & 0.1500 & 0.1500 & 0.1500 \\
$\mathrm{~N}_{2}$ & 0.0200 & 0 & 0.0310 & 0.0420 & 0.0910 & 0.0950 & 0.0950 & 0.0950 & 0.0950 & 0.1200 & 0.1200 & 0.1200 & 0.1200 \\
$\mathrm{CH}_{4}$ & 0.1030 & 0.0310 & 0 & 0.0027 & 0.0085 & 0.0158 & 0.0148 & 0.0209 & 0.0206 & 0.0253 & 0.0314 & 0.0426 & 0.0561 \\
$\mathrm{C}_{2} \mathrm{H}_{6}$ & 0.1300 & 0.0420 & 0.0027 & 0 & 0.0017 & 0.0055 & 0.0049 & 0.0087 & 0.0086 & 0.0117 & 0.0160 & 0.0245 & 0.0352 \\
$\mathrm{C}_{3} \mathrm{H}_{8}$ & 0.1350 & 0.0910 & 0.0085 & 0.0017 & 0 & 0.0011 & 0.0001 & 0.0028 & 0.0027 & 0.0046 & 0.0075 & 0.0136 & 0.0219 \\
$\mathrm{iC}_{4} \mathrm{H}_{10}$ & 0.1300 & 0.0950 & 0.0158 & 0.0055 & 0.0011 & 0 & 0.0000 & 0.0004 & 0.0004 & 0.0012 & 0.0028 & 0.0069 & 0.0133 \\
$\mathrm{nC}_{4} \mathrm{H}_{10}$ & 0.1300 & 0.0950 & 0.0148 & 0.0049 & 0.0001 & 0.0000 & 0 & 0.0006 & 0.0005 & 0.0015 & 0.0033 & 0.0077 & 0.0143 \\
$\mathrm{iC}_{5} \mathrm{H}_{12}$ & 0.1250 & 0.0950 & 0.0209 & 0.0087 & 0.0028 & 0.0004 & 0.0006 & 0 & 0.0000 & 0.0002 & 0.0011 & 0.0041 & 0.0093 \\
$\mathrm{nC}_{5} \mathrm{H}_{12}$ & 0.1250 & 0.0950 & 0.0206 & 0.0086 & 0.0027 & 0.0004 & 0.0005 & 0.0000 & 0 & 0.0003 & 0.0012 & 0.0042 & 0.0094 \\
$\mathrm{C}_{6} \mathrm{H}_{14}$ & 0.1500 & 0.1200 & 0.0253 & 0.0117 & 0.0046 & 0.0012 & 0.0015 & 0.0002 & 0.0003 & 0 & 0.0003 & 0.0024 & 0.0066 \\
$\mathrm{C}_{7} \sim \mathrm{C}_{8}$ & 0.1500 & 0.1200 & 0.0314 & 0.0160 & 0.0075 & 0.0028 & 0.0033 & 0.0011 & 0.0012 & 0.0003 & 0 & 0.0009 & 0.0039 \\
$\mathrm{C}_{9} \sim \mathrm{C}_{10}$ & 0.1500 & 0.1200 & 0.0426 & 0.0245 & 0.0136 & 0.0069 & 0.0077 & 0.0041 & 0.0042 & 0.0024 & 0.0009 & 0 & 0.0010 \\
$\mathrm{C}_{11+}$ & 0.1500 & 0.1200 & 0.0561 & 0.0352 & 0.0219 & 0.0133 & 0.0143 & 0.0093 & 0.0094 & 0.0066 & 0.0039 & 0.0010 & 0 \\
\hline
\end{tabular}

TABle 5: Summary of two-flash experimental data.

\begin{tabular}{ll}
\hline Gas-oil ratio $\left(\mathrm{m}^{3} / \mathrm{m}^{3}\right)$ & 869.00 \\
Gas volume factor & 0.0078 \\
Condensate oil density $\left(\mathrm{g} / \mathrm{cm}^{3}\right)$ & 0.7244 \\
The content of condensate oil $\left(\mathrm{g} / \mathrm{m}^{3}\right)$ & 702.90 \\
\hline
\end{tabular}

increases dramatically to the maximum and then decreases mildly.

The above phenomenon of the color of reservoir fluid changing from transparent golden yellow into light brown and then into reddish brown and finally into completely opaque ash black is called critical opalescence, which is shown in dotted line position in Figure 2. The critical opalescence is caused by molecular density fluctuation as a result of gas-liquid molecular movement in the gas-liquid phase change process. The reason of density fluctuation is evaporation of liquid molecules and condensation of gas molecules and the molecular motion was especially sharp fluctuations when the temperature is near the critical point. As a result, density distribution presents concavo-convex randomly distributed spatial curved surface, instead of laminar; and on the direction of the light, numerous liquidgas interfaces or gas-liquid interfaces appear. As light travels through these interfaces, a series of reflection and refraction happened, which reduces light energy gradually, resulting in critical opalescence.

In the CVD test, the sample volume at dew point pressure is identified as the constant pore volume of gas condensate reservoir, and dew point pressure to zero pressure (gauge pressure) is divided into six to eight pressure stages to simulate the depletion process in the reservoir, and the retrograde condensate liquid saturations at each pressure during the depletion process were measured under the conditions of equilibrium. Table 7 presents the retrograde condensate liquid saturation during the depletion process, which exhibits a maximum retrograde condensate liquid saturation of $34.04 \%$ of $V_{d}$ at $20 \mathrm{MPa}$.

4.2. Simulated Results and Discussion. In order to further study the phase behavior characteristics of reservoir fluid of H2-3 well, first of all, we used the PREOS, which adjusts the parameters, to fit the experiment data, and the fitting results are shown in Table 8 and Figures 3 and 4. Table 8 presents the matching results of dew point pressure and gas-oil ratio between the experimental data and calculated values. Figures 3 and 4 show the matching results of relative volume and retrograde condensate liquid saturation between the experimental data and calculated values. It can be seen from Table 8 and Figures 3 and 4 that the experimental values and the calculated values are very close; thus, the calculated results can be used to guide the phase behavior study. At the same time, on the basis of fitting the experimental data, $P-T$ phase diagram of the $\mathrm{H} 2-3$ well reservoir fluid was calculated, and the calculated results are shown in Figure 5. It can be seen from Figure 5 that the reservoir temperature and critical temperature are very close, and the reservoir temperature locates in the right side of the critical point, which shows that the reservoir fluid of $\mathrm{H} 2-3$ wells belongs to the nearcritical condensate gas reservoir. Secondly, to extend the laboratory results, a series of simulation calculations were carried out, such as the component variation of remaining fluid, condensate oil, condensate gas in CVD experiment, and reevaporation mechanism of remaining fluid with $\mathrm{CO}_{2}$ injection. 
TABLE 6: Summary of constant composition expansion experimental data at $132.4^{\circ} \mathrm{C}$.

\begin{tabular}{lcccc}
\hline Pressure/(MPa) & Gas volume/(mL) & Liquid volume/(mL) & Relative volume/ $\left(V / V_{d}\right)$ & Retrograde condensate liquid saturation/(\% of $\left.V_{d}\right)$ \\
\hline 25.53 & 16.023 & 0.00 & 0.983 & 0.00 \\
$24.48^{*}$ & 16.308 & - & 1 & - \\
24 & 16.471 & - & 1.009 & - \\
22 & 17.245 & - & 1.057 & - \\
21 & 17.938 & - & 1.099 & 40.079 \\
20 & 12.015 & 6.537 & 1.137 & 39.085 \\
19 & 12.785 & 6.375 & 1.175 & 37.833 \\
18 & 14.089 & 6.169 & 1.242 & 36.852 \\
17 & 15.469 & 6.010 & 1.317 & 35.335 \\
15 & 18.853 & 5.763 & 1.509 & 33.839 \\
13 & 24.227 & 5.519 & 1.824 & 31.865 \\
10 & 35.989 & 5.197 & 2.525 & 30.094 \\
7
\end{tabular}

* Saturation pressure.

—: liquid volume is too small and liquid volume is not measured.

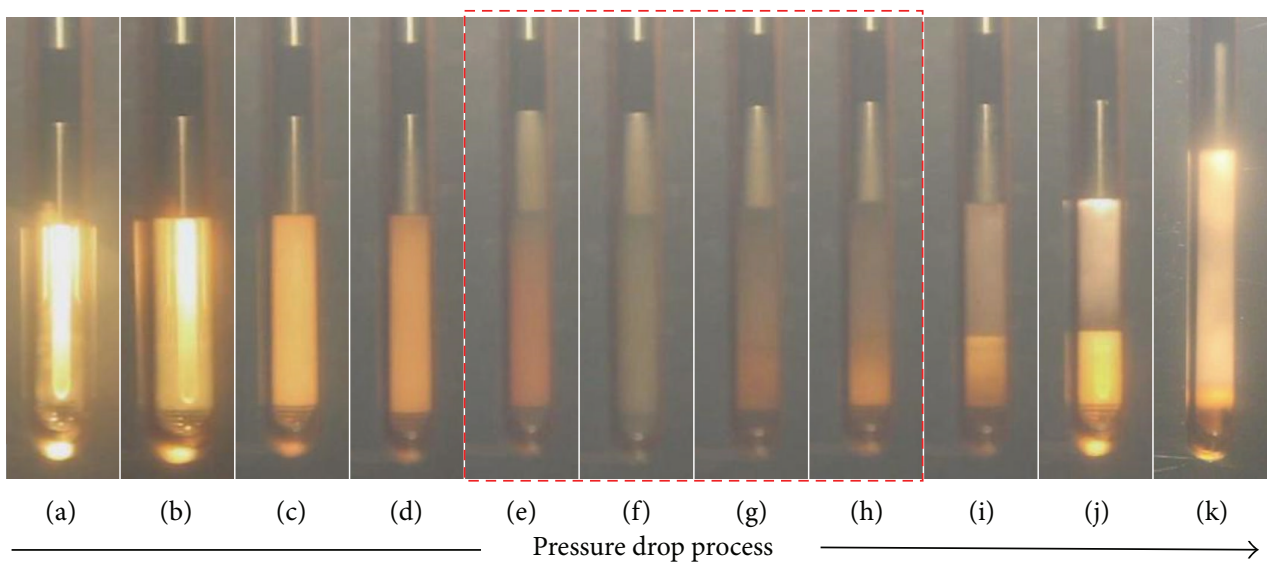

FIgURE 2: The critical opalescence phase behavior characteristics in the constant composition expansion experiment at $132.4^{\circ} \mathrm{C}$ for $\mathrm{H} 2-3 \mathrm{well}$. (a) $25.53 \mathrm{MPa}$, (b) $25 \mathrm{MPa}$, (c) $24.8 \mathrm{MPa}$, (d) $24.7 \mathrm{MPa}$, (e) $24.6 \mathrm{MPa}$, (f) $24.48 \mathrm{MPa}$, (g) $24 \mathrm{MPa}$, (h) $23 \mathrm{MPa}$, (i) $20 \mathrm{MPa}$, (j) $19 \mathrm{MPa}$, and (k) $5 \mathrm{MPa}$.

TABLE 7: Summary of constant volume depletion experimental data at $132.4^{\circ} \mathrm{C}$.

\begin{tabular}{lc}
\hline Pressure/(MPa) & $\begin{array}{c}\text { Retrograde condensate } \\
\text { liquid saturation/ }\left(\% \text { of } V_{d}\right)\end{array}$ \\
\hline 25.53 & 0 \\
$24.48^{*}$ & - \\
22 & - \\
20 & 34.04 \\
17 & 29.77 \\
14 & 29.58 \\
11 & 26.83 \\
8 & 25.22 \\
5 & 21.29 \\
\hline
\end{tabular}

${ }^{*}$ Saturation pressure.

-: liquid volume is too small and liquid volume is not measured.
Through simulation and calculation of the CVD experiment, the composition of remaining fluid along with condensate oil and gas was obtained under different pressures (ranged from $24.48 \mathrm{MPa}$ (dew point) to $5 \mathrm{MPa}$ ), and the results are presented in Tables 9 11. As is shown in Tables 9, 10 , and 11 , in the remaining fluid and remaining condensate oil, the content of $\mathrm{CH}_{4}$ decreases with decreasing the pressure, while in the discharging condensate gas, the content of $\mathrm{CH}_{4}$ increases with decreasing the pressure. And the content of $C_{2} \sim C_{6}$ shows a rising trend in the composition of the remaining fluid, remaining condensate oil, and discharging condensate gas, which indicates that once pressure drops below the dew point, light hydrocarbons (such as $\mathrm{CH}_{4}$ ) escape from condensate gas system first. In the remaining condensate oil system, the content of $\mathrm{C}_{7} \sim \mathrm{C}_{10}$ is up to $74.72 \%$, and with the decrease of pressure, the content of $\mathrm{C}_{7} \sim \mathrm{C}_{10}$ has a slight decrease, while the content of $\mathrm{C}_{11+}$ increases, 
TABLE 8: Matching results of dew point pressure, gas-oil ratio between the experimental data and calculated values.

\begin{tabular}{lccc}
\hline Matching items & Experiment & Calculation & Relative error\% \\
\hline Dew point pressure $/(\mathrm{MPa})$ & 24.48 & 24.47 & 0.046 \\
Gas-oil ratio $/\left(\mathrm{m}^{3} / \mathrm{m}^{3}\right)$ & 869 & 871.12 & 0.24 \\
\hline
\end{tabular}

TABLE 9: Calculated composition of the remaining fluid under different depletion pressures.

\begin{tabular}{lcccccccc}
\hline Component/(mol\%) & $24.48 /(\mathrm{MPa})$ & $22.00 /(\mathrm{MPa})$ & $20.00 /(\mathrm{MPa})$ & $17.00 /(\mathrm{MPa})$ & $14.00 /(\mathrm{MPa})$ & $11.00 /(\mathrm{MPa})$ & $8.00 /(\mathrm{MPa})$ & $5.00 /(\mathrm{MPa})$ \\
\hline $\mathrm{CO}_{2}$ & 5.23 & 5.21 & 5.19 & 5.12 & 5.00 & 4.80 & 4.46 & 3.85 \\
$\mathrm{~N}_{2}$ & 0.64 & 0.64 & 0.63 & 0.61 & 0.59 & 0.55 & 0.49 & 0.41 \\
$\mathrm{CH}_{4}$ & 57.07 & 56.77 & 56.35 & 55.29 & 53.54 & 50.81 & 46.51 & 39.27 \\
$\mathrm{C}_{2} \mathrm{H}_{6}$ & 11.73 & 11.72 & 11.70 & 11.64 & 11.53 & 11.3 & 10.82 & 9.76 \\
$\mathrm{C}_{3} \mathrm{H}_{8}$ & 6.22 & 6.23 & 6.25 & 6.3 & 6.36 & 6.43 & 6.45 & 6.26 \\
$\mathrm{iC}_{4} \mathrm{H}_{10}$ & 1.07 & 1.07 & 1.08 & 1.10 & 1.13 & 1.16 & 1.21 & 1.25 \\
$\mathrm{nC}_{4} \mathrm{H}_{10}$ & 1.76 & 1.77 & 1.78 & 1.82 & 1.88 & 1.97 & 2.09 & 2.22 \\
$\mathrm{iC}_{5} \mathrm{H}_{12}$ & 1.21 & 1.22 & 1.23 & 1.27 & 1.34 & 1.44 & 1.58 & 1.8 \\
$\mathrm{nC}_{5} \mathrm{H}_{12}$ & 1.09 & 1.10 & 1.11 & 1.15 & 1.21 & 1.31 & 1.46 & 1.69 \\
$\mathrm{C}_{6} \mathrm{H}_{14}$ & 2.58 & 2.61 & 2.66 & 2.77 & 2.98 & 3.30 & 3.82 & 4.70 \\
$\mathrm{C}_{7} \sim \mathrm{C}_{8}$ & 7.74 & 7.87 & 8.06 & 8.57 & 9.45 & 10.89 & 13.33 \\
$\mathrm{C}_{9} \sim \mathrm{C}_{10}$ & 2.49 & 2.54 & 2.64 & 2.85 & 3.23 & 3.85 & 4.90 & 17.8 \\
$\mathrm{C}_{11+}$ & 1.18 & 1.25 & 1.32 & 1.51 & 1.76 & 2.19 & 2.88 & 6.88 \\
\hline
\end{tabular}

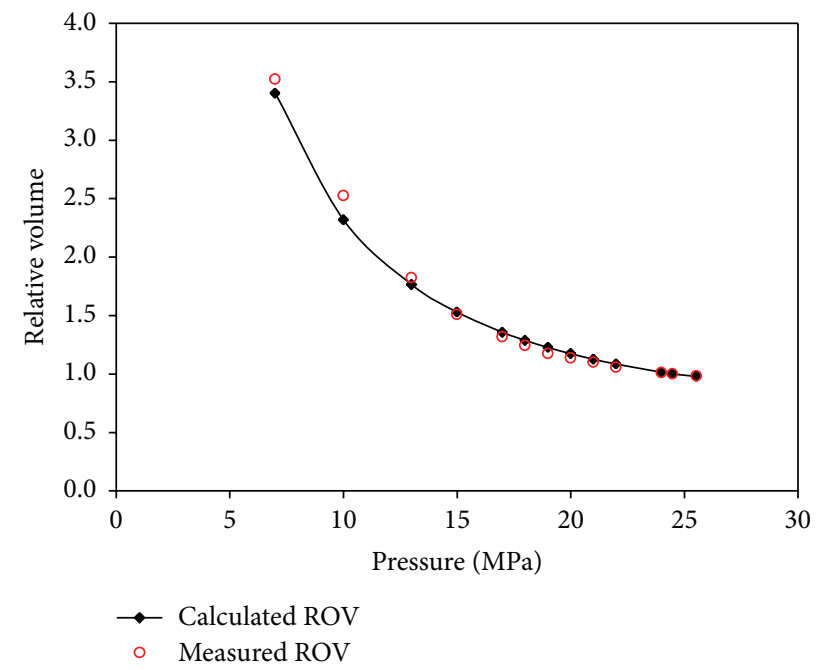

FIGURE 3: Matching results of relative volume between the experimental data and calculated values.

which indicates that part of the heavy hydrocarbons $\left(\mathrm{C}_{7} \sim \mathrm{C}_{10}\right)$ reevaporate from the condensate oil when depleting to a certain pressure. In general, with the decrease of pressure, the heavy component shows a rising trend in the remaining fluid.

On the basis of composition analysis, phase diagrams and retrograde condensate characteristics of reservoir fluid under different pressures have been simulated and calculated. Figure 6 shows the two-phase boundaries of remaining fluid of different depletion pressure. It can be seen from Figure 6 that, with the decrease of pressure, phase diagram becomes

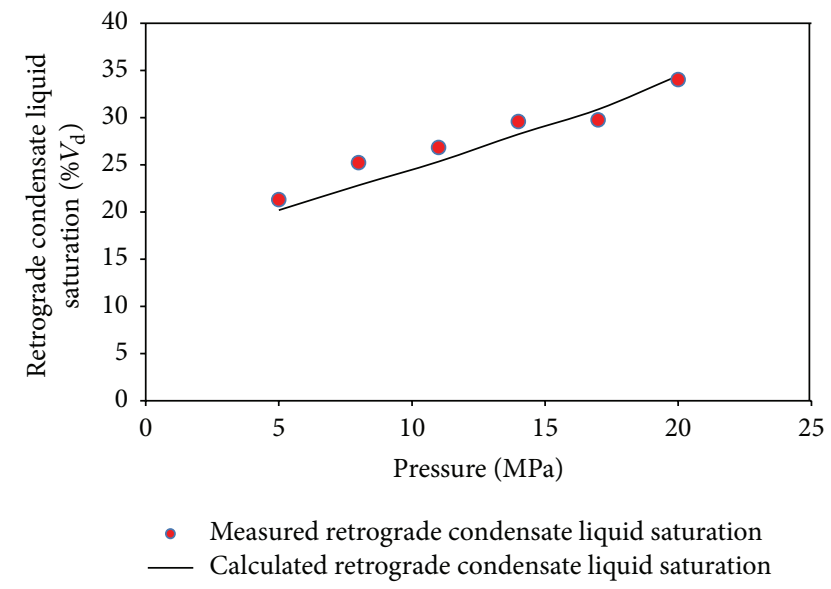

FIGURE 4: Matching results of retrograde condensate liquid saturation between the experimental data and calculated values.

more wide and narrow to the right and critical point moves to the lower right. And when pressure drops below the $17 \mathrm{MPa}$, the critical temperature of the remaining fluid system is above the reservoir temperature $\left(132.4^{\circ} \mathrm{C}\right)$, and the remaining fluid is considered to shift from condensate gas reservoir system into a volatile oil system. The variation relationship between the retrograde condensate liquid saturation and pressure is shown in Figure 7. It can be clearly seen that in the remaining fluids at $22 \mathrm{MPa}, 20 \mathrm{MPa}$, and $17 \mathrm{MPa}$, with the decrease of pressure, the retrograde condensate liquid saturations increase at first and then decrease, which indicates that the remaining reservoir fluids appear as the phase behavior of condensate gas system. And when pressure drops below 
TABLE 10: Calculated composition of the remaining condensate oil under different depletion pressures.

\begin{tabular}{lcccccccc}
\hline Component/(mol\%) & $24.48 /(\mathrm{MPa})$ & $22.00 /(\mathrm{MPa})$ & $20.00 /(\mathrm{MPa})$ & $17.00 /(\mathrm{MPa})$ & $14.00 /(\mathrm{MPa})$ & $11.00 /(\mathrm{MPa})$ & $8.00 /(\mathrm{MPa})$ & $5.00 /(\mathrm{MPa})$ \\
\hline $\mathrm{CO}_{2}$ & $/$ & 0.08 & 0.08 & 0.08 & 0.08 & 0.08 & 0.08 \\
$\mathrm{~N}_{2}$ & $/$ & 0.00 & 0.00 & 0.00 & 0.00 & 0.00 & 0.00 & 0.00 \\
$\mathrm{CH}_{4}$ & $/$ & 0.38 & 0.38 & 0.38 & 0.37 & 0.37 & 0.36 & 0.35 \\
$\mathrm{C}_{2} \mathrm{H}_{6}$ & $/$ & 0.44 & 0.44 & 0.44 & 0.45 & 0.46 & 0.47 & 0.48 \\
$\mathrm{C}_{3} \mathrm{H}_{8}$ & $/$ & 0.87 & 0.88 & 0.90 & 0.92 & 0.96 & 1.02 & 1.11 \\
$\mathrm{iC}_{4} \mathrm{H}_{10}$ & $/$ & 0.39 & 0.39 & 0.40 & 0.41 & 0.44 & 0.48 & 0.53 \\
$\mathrm{nC}_{4} \mathrm{H}_{10}$ & $/$ & 0.87 & 0.88 & 0.91 & 0.95 & 1.01 & 1.10 & 1.25 \\
$\mathrm{iC}_{5} \mathrm{H}_{12}$ & $/$ & 1.49 & 1.50 & 1.54 & 1.61 & 1.72 & 1.87 \\
$\mathrm{nC}_{5} \mathrm{H}_{12}$ & $/$ & 1.70 & 1.71 & 1.76 & 1.83 & 1.94 & 2.09 \\
$\mathrm{C}_{6} \mathrm{H}_{14}$ & $/$ & 8.41 & 8.46 & 8.58 & 8.79 & 9.08 & 9.44 & 2.08 \\
$\mathrm{C}_{7} \sim \mathrm{C}_{8}$ & $/$ & 53.52 & 53.24 & 52.72 & 52.11 & 51.43 & 50.61 \\
$\mathrm{C}_{9} \sim \mathrm{C}_{10}$ & $/$ & 21.20 & 21.12 & 20.97 & 20.81 & 20.63 & 20.43 \\
$\mathrm{C}_{11+}$ & $/$ & 10.65 & 10.92 & 11.32 & 11.67 & 11.88 & 12.05 & 20.73 \\
\hline
\end{tabular}

/: there is no remaining condensate oil, because the calculated saturation pressure is $24.47 \mathrm{MPa}$ and the measured saturation pressure is $24.48 \mathrm{MPa}$.

TABLE 11: Calculated composition of the discharging condensate gas under different depletion pressures.

\begin{tabular}{|c|c|c|c|c|c|c|c|c|}
\hline Component/(mol\%) & $24.48 /(\mathrm{MPa})$ & $22.00 /(\mathrm{MPa})$ & $20.00 /(\mathrm{MPa})$ & $17.00 /(\mathrm{MPa})$ & $14.00 /(\mathrm{MPa})$ & $11.00 /(\mathrm{MPa})$ & $8.00 /(\mathrm{MPa})$ & $5.00 /(\mathrm{MPa})$ \\
\hline $\mathrm{CO}_{2}$ & l & 0.68 & 0.69 & 0.71 & 0.72 & 0.72 & 0.72 & 0.72 \\
\hline $\mathrm{N}_{2}$ & l & 6.08 & 6.25 & 6.34 & 6.31 & 6.18 & 5.96 & 5.57 \\
\hline $\mathrm{CH}_{4}$ & l & 62.52 & 63.93 & 65.18 & 65.82 & 65.92 & 65.34 & 63.50 \\
\hline $\mathrm{C}_{2} \mathrm{H}_{6}$ & I & 11.85 & 11.94 & 12.11 & 12.33 & 12.62 & 13.01 & 13.51 \\
\hline $\mathrm{C}_{3} \mathrm{H}_{8}$ & l & 5.88 & 5.82 & 5.82 & 5.9 & 6.08 & 6.42 & 7.04 \\
\hline $\mathrm{iC}_{4} \mathrm{H}_{10}$ & I & 0.97 & 0.94 & 0.93 & 0.93 & 0.95 & 1.01 & 1.15 \\
\hline $\mathrm{nC}_{4} \mathrm{H}_{10}$ & l & 1.54 & 1.49 & 1.46 & 1.45 & 1.49 & 1.58 & 1.82 \\
\hline $\mathrm{iC}_{5} \mathrm{H}_{12}$ & l & 1.00 & 0.95 & 0.9 & 0.88 & 0.89 & 0.94 & 1.1 \\
\hline $\mathrm{nC}_{5} \mathrm{H}_{12}$ & l & 0.89 & 0.84 & 0.79 & 0.76 & 0.76 & 0.81 & 0.94 \\
\hline $\mathrm{C}_{6} \mathrm{H}_{14}$ & l & 1.97 & 1.8 & 1.63 & 1.53 & 1.49 & 1.54 & 1.8 \\
\hline $\mathrm{C}_{7} \sim \mathrm{C}_{8}$ & I & 5.03 & 4.26 & 3.49 & 2.97 & 2.62 & 2.47 & 2.7 \\
\hline $\mathrm{C}_{9} \sim \mathrm{C}_{10}$ & I & 1.05 & 0.71 & 0.43 & 0.27 & 0.17 & 0.12 & 0.1 \\
\hline $\mathrm{C}_{11+}$ & 1 & 0.53 & 0.37 & 0.23 & 0.15 & 0.1 & 0.07 & 0.06 \\
\hline
\end{tabular}

/: there is not remaining discharging condensate gas, because the calculated saturation pressure is $24.47 \mathrm{MPa}$ and the measured saturation pressure is $24.48 \mathrm{MPa}$.

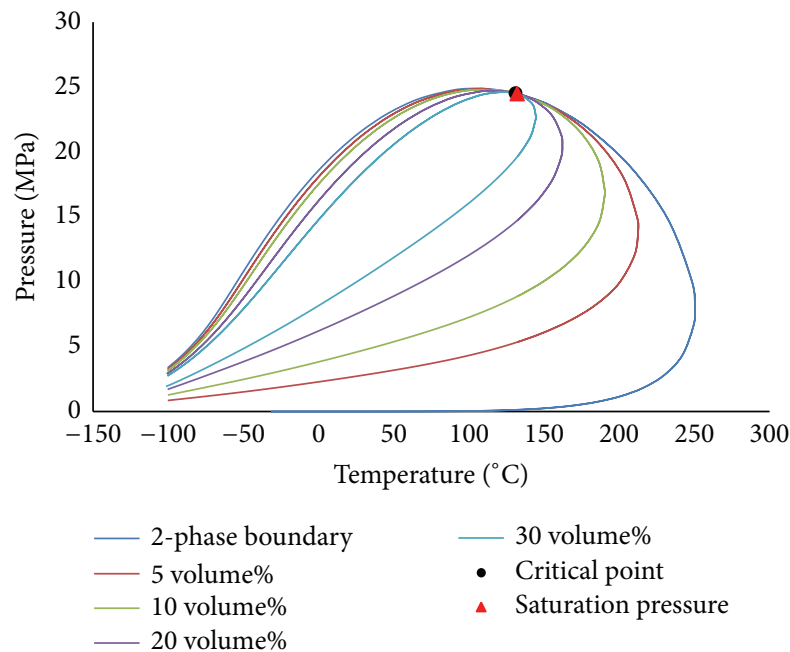

FIGURE 5: Calculated phase diagram of reservoir fluid of H2-3 well. the $17 \mathrm{MPa}$, the retrograde condensate liquid saturations decrease with decreasing the pressure, which indicates that the remaining reservoir fluids exhibit the phase behavior of volatile oil system.

In addition, we performed the simulation of phase behavior of remaining fluid with $\mathrm{CO}_{2}$ injection, and the remaining fluid at $22 \mathrm{MPa}$ is selected. Then, the remaining fluid was mixed with $\mathrm{CO}_{2}$ of $20 \mathrm{~mol} \%, 40 \mathrm{~mol} \%, 60 \mathrm{~mol} \%$, $70 \mathrm{~mol} \%$, and $80 \mathrm{~mol} \%$, respectively. The dew point and the retrograde condensate liquid saturation of the mixed system were calculated. The calculated results are presented in Figures 8 and 9. Figures 8 and 9 illustrate that with the increase of $\mathrm{CO}_{2}$ injected quantity, the retrograde condensate liquid saturation decreases and at $80 \mathrm{~mol} \% \mathrm{CO}_{2}$ injected quantity, the maximum condensate saturation is only about $2.47 \%$. Compared with the original remaining fluid at $22 \mathrm{MPa}$, the retrograde condensate liquid saturation is significantly reduced, which explains the reevaporation mechanism of 


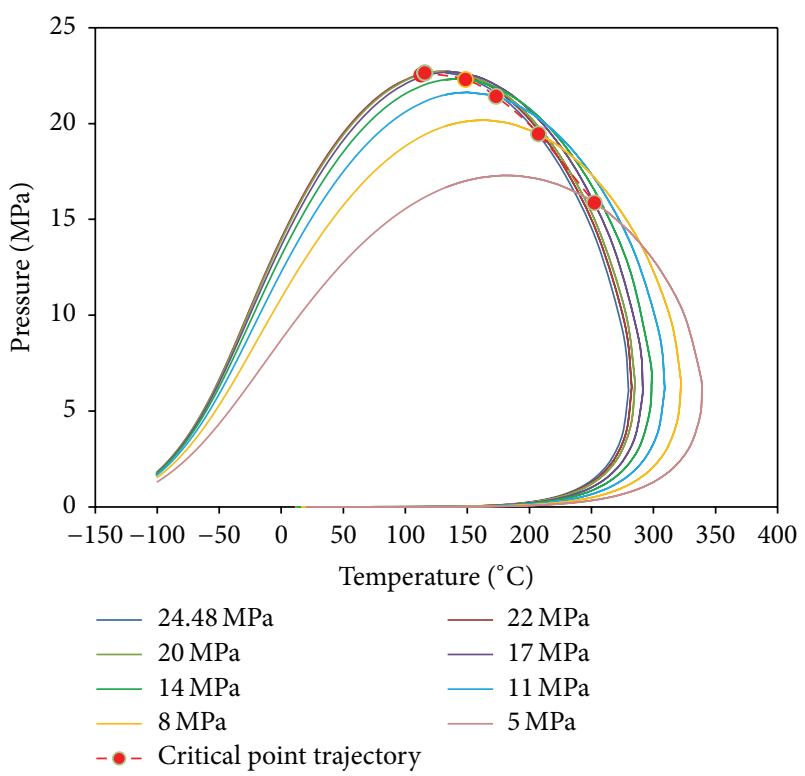

FIGURE 6: Calculated two-phase boundaries of resident fluid under different depletion pressures.

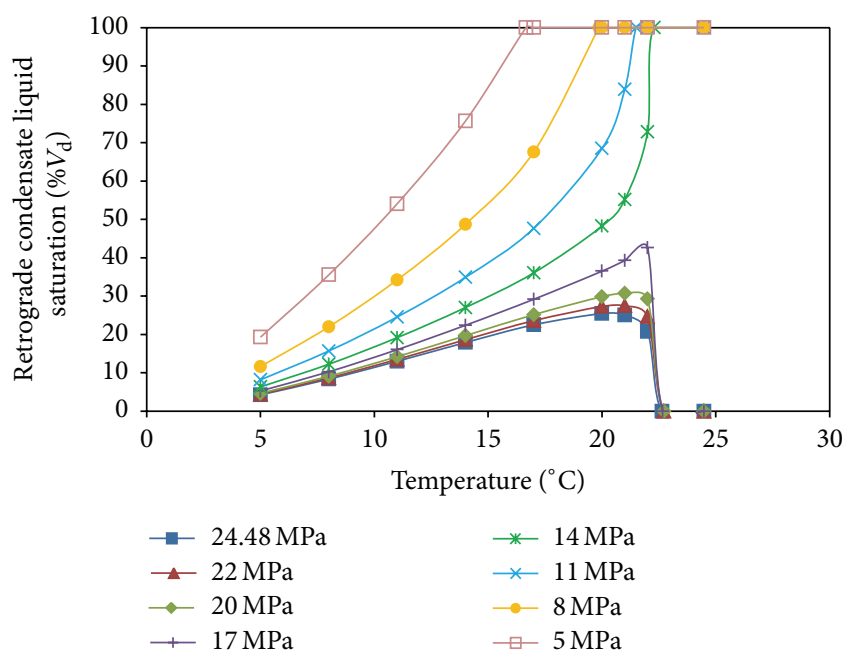

FIGURE 7: Calculated retrograde condensate liquid saturation under different depletion pressures.

remaining fluid with $\mathrm{CO}_{2}$ injection. As to dew point pressure, with the increase of $\mathrm{CO}_{2}$ injected quantity, the dew point pressure increases first and then decreases.

\section{Conclusions}

(1) The reservoir fluid of H2-3 well is considered to be the near-critical condensate gas reservoir system combined with the well stream components and $P-T$ phase diagram.

(2) In the vicinity of the critical region, the reservoir fluid of H2-3 well appears as the "critical opalescence" phenomenon, and the phenomenon is caused by the

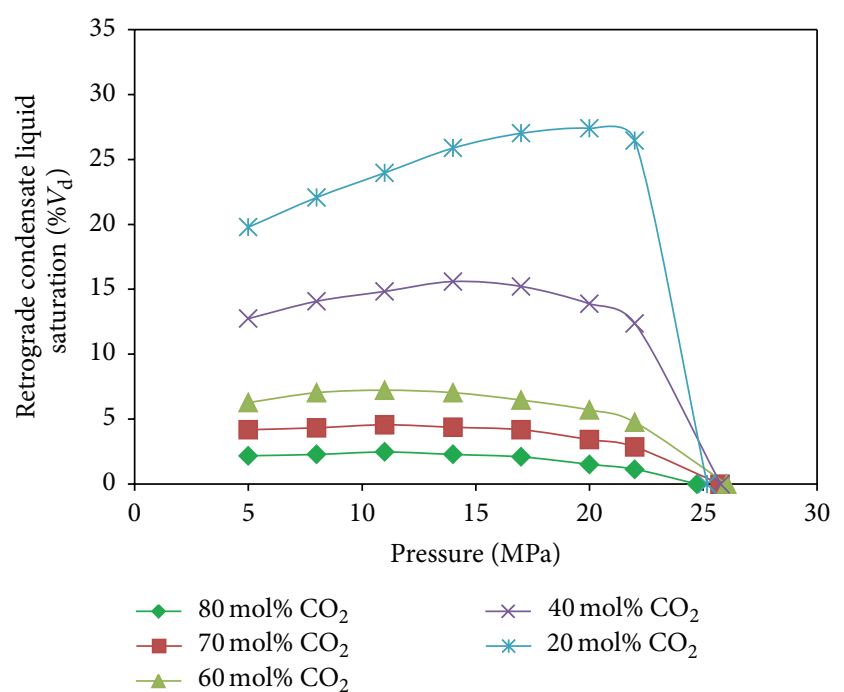

FIGURE 8: The variation of calculated retrograde condensate liquid saturation with $\mathrm{CO}_{2}$ injected quantity.

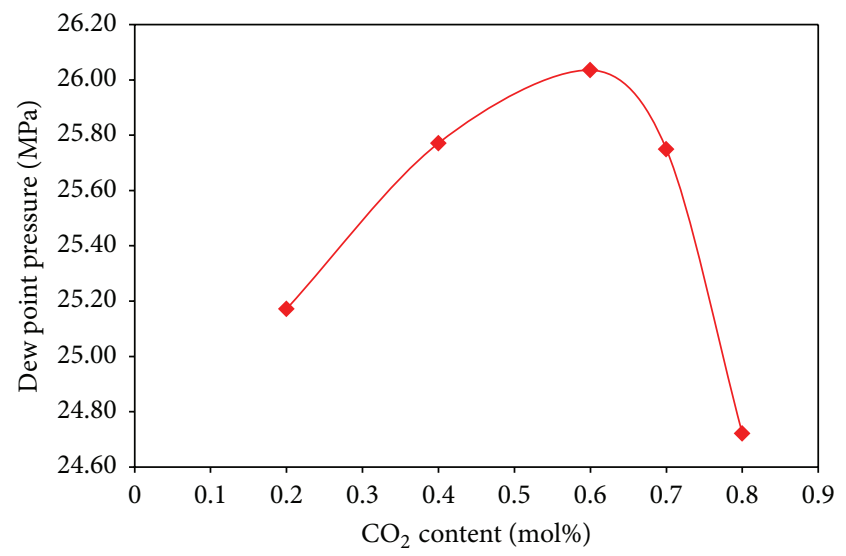

FIGURE 9: The variation of calculated dew point pressure with $\mathrm{CO}_{2}$ injected quantity.

density fluctuations in the gas and liquid molecular motion during the gas-liquid phase change process.

(3) The volume of retrograde condensate liquid saturation during the depletion process increases first and then decreases, and when reservoir pressure drops below a certain pressure, the variation of retrograde condensate liquid saturation exhibits the phase behavior of volatile oil.

(4) The reevaporation of remaining fluid consists of two aspects: (1) part of heavy hydrocarbons reevaporate from the remaining condensate oil when depleting to a certain pressure; (2) the variation characteristics of retrograde condensate liquid saturation of remaining fluid shift from a condensate gas condensate system into a volatile oil system.

(5) The recovery of condensate oil and gas is proportional to the $\mathrm{CO}_{2}$ injected quantity. 
(6) When implementing $\mathrm{CO}_{2}$ injection in the nearcritical condensate gas reservoir, the dew point pressure of the new mixed fluid system should be taken into account, since it is not simply monotonically increasing or decreasing with the increase of $\mathrm{CO}_{2}$ injected quantity.

\section{Competing Interests}

Here, all the authors solemnly declare that there are no competing interests regarding the publication of this paper.

\section{Acknowledgments}

The authors wish to acknowledge anonymous reviewers for constructive comments and suggestions for improving this paper. The authors also wish to thank the anonymous Associate Editor for his handling of the paper and additional suggestions. This work was supported by Open Fund (PLN1509) of State Key Laboratory of Oil and Gas Reservoir Geology and Exploitation (Southwest Petroleum University) and the Fund of the Department of Education in Sichuan (no. 15ZB0065).

\section{References}

[1] L. Sun, H. Zhao, S. B. Kiselev, and C. McCabe, "Predicting mixture phase equilibria and critical behavior using the SAFTVRX approach," Journal of Physical Chemistry B, vol. 109, no. 18, pp. 9047-9058, 2005.

[2] W. Yan, L.-K. Wang, L.-Y. Yang, and T.-M. Guo, "A systematic experimental study on the phase behavior of complex fluid mixtures up to near-critical region," Fluid Phase Equilibria, vol. 190, no. 1-2, pp. 159-178, 2001.

[3] L. Gil, J. F. Martínez-López, M. Artal et al., "Volumetric behavior of the $\mathrm{CO}_{2}(1)+\mathrm{C}_{2} \mathrm{H}_{6}$ (2) system in the subcritical ( $T=$ $293.15 \mathrm{~K})$, critical, and supercritical $(T=308.15 \mathrm{~K})$ regions," The Journal of Physical Chemistry B, vol. 114, no. 1, pp. 5447-5469, 2010.

[4] A. R. Bazaev and E. A. Bazaev, "The thermodynamic properties of binary mixtures of technologically important substances in the near- and supercritical states," Russian Journal of Physical Chemistry B, vol. 4, no. 8, pp. 1178-1187, 2010.

[5] T. Yang, W.-D. Chen, and T.-M. Guo, "Phase behavior of a nearcritical reservoir fluid mixture," Fluid Phase Equilibria, vol. 128, no. 1-2, pp. 183-197, 1997.

[6] K. Luo and T. Zhong, "A discussion on the layering of nearcritical gas condensate in PVT cell," Petroleum Exploration and Development, vol. 26, no. 1, pp. 68-70, 1999.

[7] P. Shen, K. Luo, X. Zheng, S. Li, Z. Dai, and H. Liu, "Experimental study of near-critical behavior of gas condensate systems," in Proceedings of the SPE Production and Operations Symposium, SPE 67285, Oklahoma City, Okla, USA, March 2001.

[8] X. Zheng, P. Sheng, S. Li, K. Luo, and Z. Dai, "Experimental investigation into near-critical phenomena of rich gas condensate systems," in Proceedings of the SPE International Oil and Gas Conference and Exhibition in China (iOGCEC '00), SPE64712, pp. 459-468, Beijing, China, November 2000.

[9] P. P. Shen, X. T. Zheng, S. Li, K. Luo, and W. Y. Sun, "Near-critical phenomenal of rich gas condensate system: an experimental investigation," Acta Petrolei Sinica, vol. 22, no. 3, pp. 47-51, 2001.
[10] C.-A. C. Parra and J.-C.-M. E. Remolina, "Experimental study and calculations of the near critical behavior of a synthetic fluid in nitrogen injection," Ciencia Tecnología y Futuro, vol. 3, no. 1, pp. 127-137, 2005.

[11] H.-Y. Chiu, R.-F. Jung, M.-J. Lee, and H.-M. Lin, "Vapor-liquid phase equilibrium behavior of mixtures containing supercritical carbon dioxide near critical region," Journal of Supercritical Fluids, vol. 44, no. 3, pp. 273-278, 2008.

[12] M. N. Shehata, S.-E. K. Fateen, and A. Bonilla-Petriciolet, "Critical point calculations of multi-component reservoir fluids using nature-inspired metaheuristic algorithms," Fluid Phase Equilibria, vol. 409, pp. 280-290, 2016.

[13] H.-G. Li, X.-Y. Lu, and V. Yang, "A numerical study of fluid injection and mixing under near-critical conditions," Acta Mechanica Sinica, vol. 28, no. 3, pp. 559-571, 2012.

[14] L. Mistura, "Transport coefficients near a critical point in multicomponent fluid systems," Il Nuovo Cimento, vol. 12, no. 1, pp. 35-42, 1972.

[15] J.-N. Jaubert, L. Avaullee, and C. Pierre, "Is it still necessary to measure the minimum miscibility pressure?" Industrial \& Engineering Chemistry Research, vol. 41, no. 2, pp. 303-310, 2002.

[16] China National Oil and Gas Industry Standards, "Analysis for reservoir fluids physical properties," Tech. Rep. SY/T5542-2009, 2009.

[17] D.-Y. Peng and D. B. Robinson, "A new two-constant equation of state," Industrial \& Engineering Chemistry Fundamentals, vol. 15 , no. 1, pp. 59-64, 1976. 

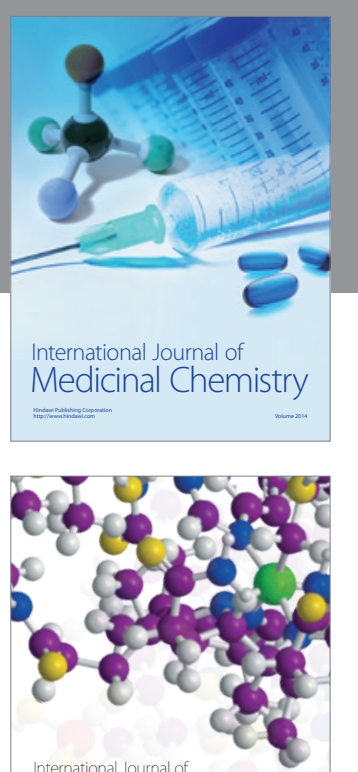

Carbohydrate Chemistry

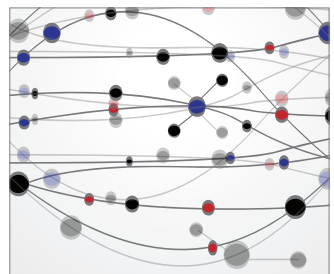

The Scientific World Journal
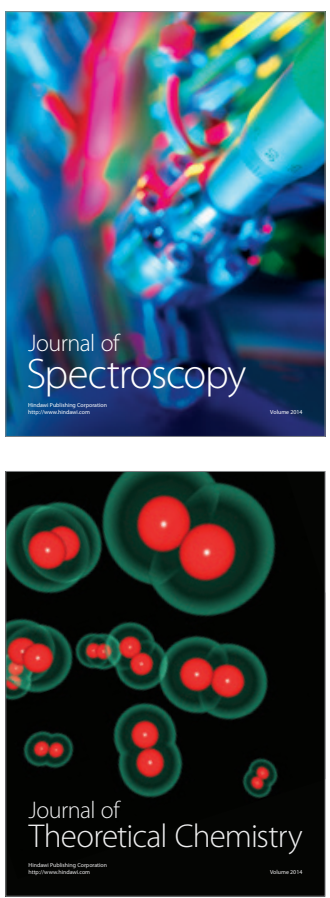
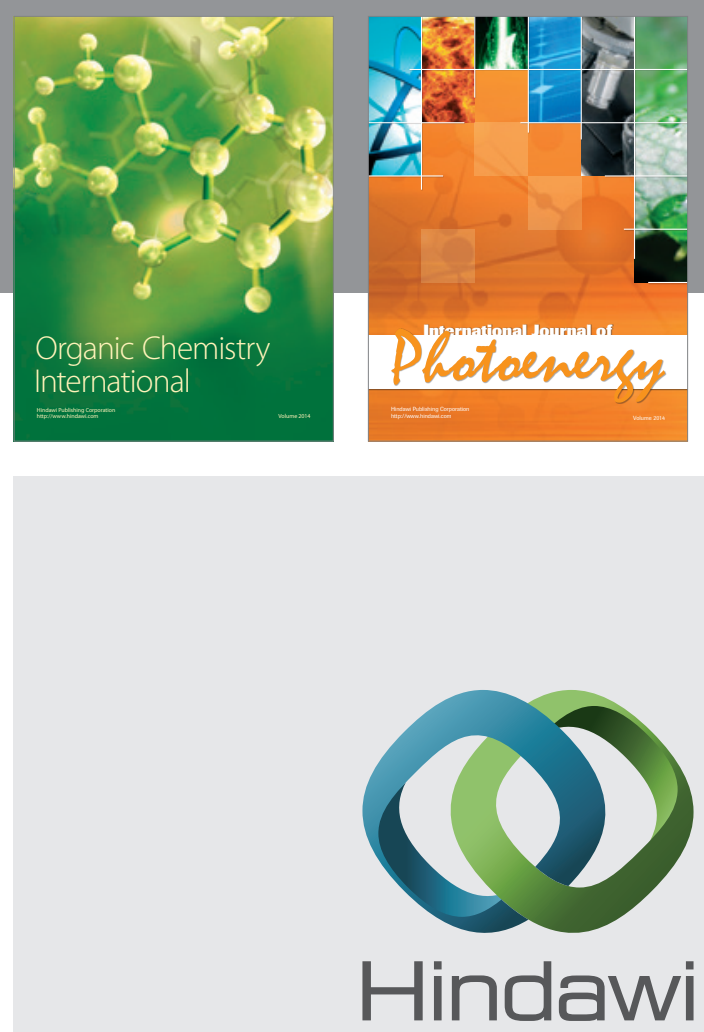

Submit your manuscripts at

http://www.hindawi.com

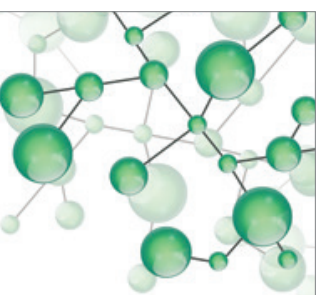

International Journal of

Inorganic Chemistry

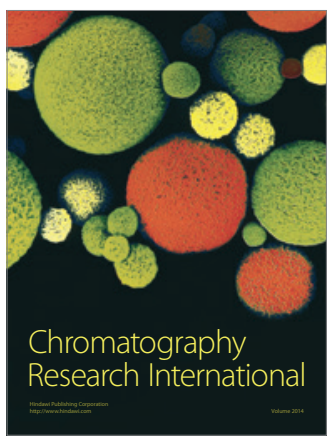

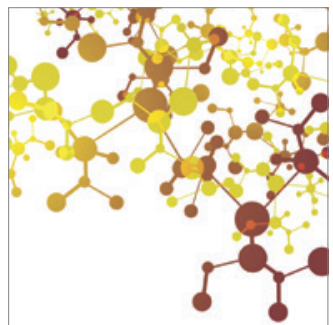

Applied Chemistry
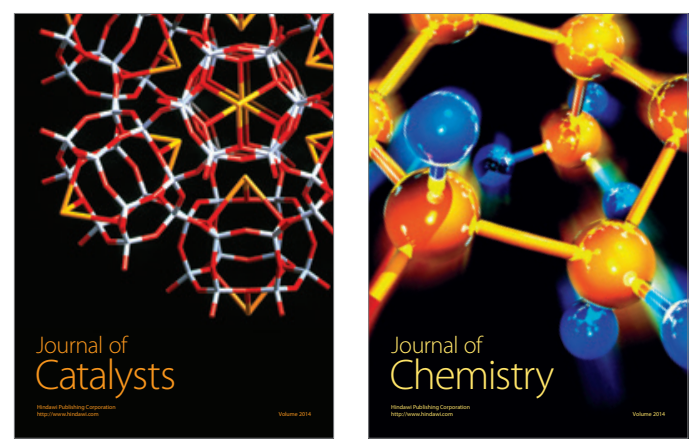
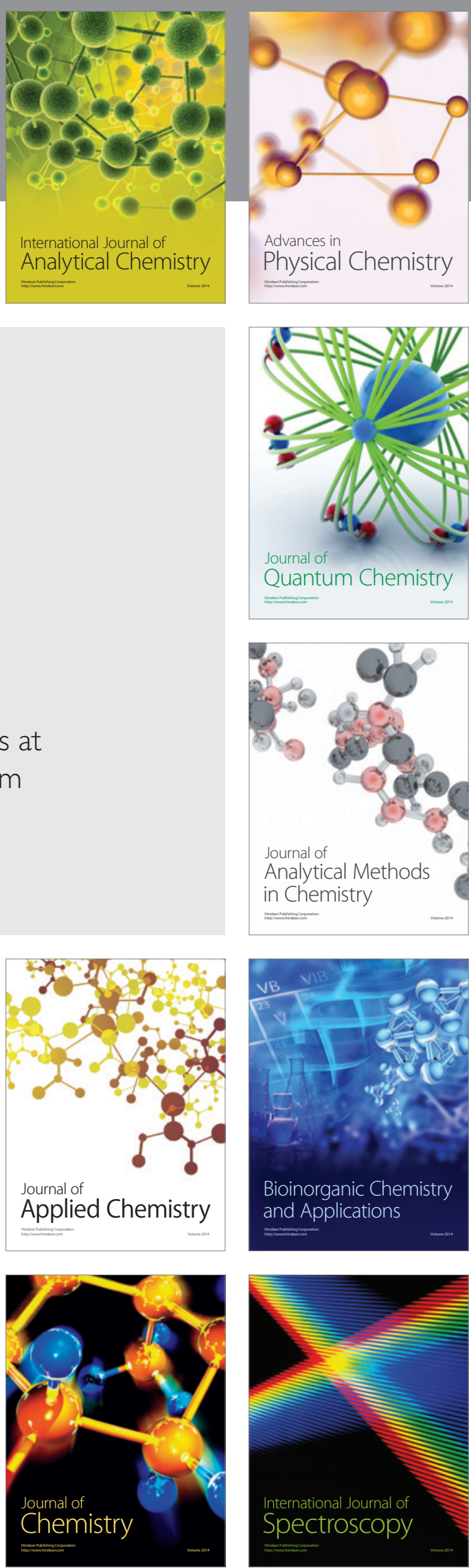